\title{
Assessing the Practices of Public Relations: The Case of Seka District Communication Office at Jimma Zone, Ethiopia
}

\author{
Eyasu Yaya Sada \\ Department of English Language and Literature, College of Social \\ Sciences and Humanities, Bonga University, Ethiopia, P.O.Box: 334, Bonga
}

\begin{abstract}
The overall objective of the study was to assess the practices of PR in the communication office of Seka Chekorsa district at Jimma Zone. The research was conducted using both qualitative and quantitative approaches. The data was collected from questionnaire, interview and document analysis. Questionnaire participants were the international and external publics of the Seka district communication office, and they were selected using convenience sampling. The two PR practionnaires were purposefully selected from the communication office of the district. With regard to data collected from questionnaire, it was tabulated and analyzed quantitatively using percentage in numbers. And the information that was gathered from interview and document analysis was analyzed qualitatively by using narration and description. Based on analyzed and interpreted data, the practices of PR in Seka Chekorsa are good especially in establishing and maintaining relationship, and in creating friendly atmosphere of communication between organization and publics (internal and external publics). However, it is not effective because of some problems like lack of professional man power, working material and enough budgets. Therefore, to overcome such problems and to make department functions more, the organization must give much attention to facilitate supportive mechanisms to the department. The researcher recommended that the concerned bodies should employ PR practitioners who are skilled in the field of language, journalism and communication, and the department has to have its own communication sector instead of working depending on other's media for the far betterment of the practice of PR in the office.
\end{abstract}

Keywords: Public Relations (PR), Communication, Practice, Seka Chekorsa, Distict

DOI: $10.7176 / \mathrm{NMMC} / 85-04$

Publication date: November $30^{\text {th }} 2019$

\subsection{Introduction}

"Public relations practice is the planned and sustained effort to establish and maintain good will and mutual understanding between and organization and its publics" (Brands, 2007:187). Often PR uses the news or business press to carry positive stories about the company and/or person cultivating a good relationship with local press representatives and its public

Public relations activities include helping the public to understand the company and its products and/or a media. For example, newspapers, television, magazines, business press etc, and often considered one of the primary activities included in promotions (Free Management library, 2007:241). According to Bernays (1945), one of the pioneers of PR stated that three main elements of public relations are practically as old as society: informing people, persuading people, or integrating people with people.

"PR also encompasses many areas and includes both the internal and external publics and with vague definitions: PR has an open forum for activities in the process for success" (Seital, 2004:79).

The great part of public relations is conducting outside the commercial world relation has large roles to play in not for profit organization. Principally, because of the increased accounting placed on different manners in such organization like central and local government trade union professional institution of the police, the armed force the fire and ambulance brigade (Jefkin, 2004).

Any organization has big or small, governmental or non-governmental need to have public relations staff so as to achieve its goal successfully. Public relations activities are crucial not only for profit earning organization but also for awareness creation about publics in order to achieve their objectives.

Hence, nowadays, many Ethiopian's organizations have established their own public relations departments. Among them, Seka Chekorsa district is the one that established public relation department aimed at giving information and creating awareness for publics in the district. And it also paves the way for better communication and understanding between the organization and the publics. Therefore, it is necessary to examine the respective development in view of practices of public relations in the district.

\section{2 .Statement of the Problem}

Various research works have shown that there are a few studies that have been conducted in the area of public relations in Ethiopia. For instance, Selfedin Aferano(2014) conducted assessing the Communication Strategies of Public Relations Office of Adama City Administration and Zelalem Dejene(2014) conducted assessment on the factors that affect Melele City Culture and Tourism due to lack of Public Relations Service. But this study 
stresses on the practices of PR ; it does not totally focus on communication and factors that hinder PR department. To fill the gap, the researcher is inspired to embark on this study. In Ethiopia, public relations practice is not successful and/or effective.

The researcher also tried to observe public relations practices of Seka Chekorsa district during his Community Based Trained Program(CBTP) field work and observed problems, or challenges of PR department there. The organization, PR department carries out activities in so many Kebeles. This shows that the department has a wide range of coverage and varieties of activities.

According to Baran (2002:214) to organize the operation of PR, he categorizes the activities of practitioners in to various positions such as executive accountant, executive, creative specialist, media governmental relation, large public relations operation, research governmental relation and financial relation. But, in Seka Chekorsa district's communication office, there is no such kind of work division.

Therefore, the core of this study is to investigate problems and the practices of public relations carries out in Seka Chekorsa district's communication office.

\subsection{Basic Research Questions}

This study tried to answer the following questions:

(i) What could be the factors that hinder the public relations officers from performing proper activities in Seka Chekorsa District?

(ii) What would be the duties and responsibilities of the PR practitioners in Seka Communication Office?

(iii) What could be the contribution of the department with regard to facilitating communication within the internal and external publics of the organization?

\subsection{Objectives of the Study}

\subsection{General Objective}

The general objective of the study is to investigate the practices of PR in communication office of Seka Chekorsa district.

\subsection{Specific Objectives}

The specific objectives of the study were to:

(i) Identify the challenges PR officers in connection with the practices of public relations in Seka Chekorsa Communication office;

(ii) Assess the duties and responsibilities of the PR department in Seka Chekorsa District;

(iii) Investigate the contributions of the department with regard to facilitating communication within the internal and external publics of the organization.

\section{Review of Related Literature}

\subsection{What is Public Relations (PR)?}

There are many definitions of public relations and the basic definition is typically the same.

According to Barany (2002) public relations is a management function that focuses on the relationship and communications that individual and organizations have with other groups (called publics) for the purpose of creating mutual good will.

This definition highly depends on two elements: "Communication and management". This shows the interdependence among public relations, communication and management. From this, we can understand that management cannot stand alone; public relations is also function of management, and plays communicative role among the organization and the public. And communication is an essential element for both management and public relations. Without communication, both can not exist.

Jefkins (2004:7) provides the definition of public relations based on "Mexican statement." This statement is drawn from an international conference of public relations organization held in Mexico City in 1978. The definition emphasizes the role of research design of public relations program.

"Public relations practice is the art and social sciences of analyzing friends, predicting their consequences, counseling organization leaders and implementing planned programs of action that will serve both organizations and the public interest" (Jefkins, 2004:7).

The statement above spells out clearly that full role of PR with nature and also shows the responsibilities of the publication function by five important aspects in the public relations process. These aspects are:

Analysis of trends: public relations campaign needs to be planned with full understanding of the friends that will influence the organization future.

Predicting the consequence: this is generally referred to as the process of "issue management" PR officer's task in this regard is to identify how to react toward particular events.

Counseling leaders: the advisors role of public relations practitioners is important. There are two aspects of PR management; one is working with the top management and others in management of the 
in-house department or the consultancy and clients' services.

Implementing planned program of action: this includes opportunities to report and be flexible in circumstances where changes are fundamental to the effective PR plan.

Serving the public interest: it should be socially responsible and ethical.

Therefore, we can conclude from the earlier definition as PR covers variety of activities and it is a very wide and an important concept. This means that it deals with communication, management service and other organizational activities.

"Public relations is essentially interdisciplinary as well as applied art and social science with the primary objective of public interest instead of private reward or prefix maximization" (Daramo, 1996:1)

\subsection{The Functions of Public Relations}

According to the public relations society of America $(2009,6)$ in its official statement on public relations", PRSA goes on to clarity the functions of public relations as follows:

Public relations help our complex, pluralistic society to reach decisions and function more effectively by contributing mutual understanding among groups and institutions. It serves to bring private and public policies into harmony.

Public relations serves a wide variety of institutions in society such as business, trade unions, government a genies, voluntary associations, foundations, hospital, schools and colleges and religious institutions. To achieve their goals, these institutions much develop effective relationships with different audiences or publics such as employees, member's customers, local communities, shareholders, and other institutions and with society at large. The management of institution needs to understand the attitudes and values of their publics in order to achieve institutional goals.

The public relations practitioner acts as a counselor to management and as a mediator, helping to translate private aims into reasonable, publicly acceptable policy and action (PRSA: 2009a). And the followings are the most salient fair terms provided at all levels.

a) Human relations

The job of communication is to help and promote human relation making use of it among other things, in the media be if print or electronic. There can be no mutual understanding in human relations without communication (Ibid).

b) Empathy

Empathy is a feeling with the other person expressed by speech. Sympathy is feeling sorry for a person expressed by words.

c) Persuasion

Persuasion is a process of convincing and motivating to get things done. Speech is one of the methods to a sense of human interest towards the person who is being persuaded will understand and appreciate the cause and effect of his action.

d) Dialogue

Dialogue is a process of conversation or speech with a purpose. If involves exchanges of ideas and subsequently influencing behavior reconciliation and compromise are also generally involved (Ibid)

Dialogue is a democratic, civilized and constructive weapon. It takes the form of discussion, others viewpoints should be considered and there is no place for monopoly of the conversation in dialogue.

e) Information

In the new information of the word, information transmission is the process of getting things done. In complex business organization, effective decisions depend up on collections, storage and supply of information. Information taking and information giving is a continuous process in an organization.

f) To influence

The objective of transmitting information is to change the behavior of the recipient. Communicator is aimed at influencing, persuading, motivating or activating people towards desired goals.

g) Understanding

The main cause for conflict in an interpersonal situation is lack of mutual understanding. The problems of communication pertain mainly to the problems of understanding people. The most important managerial function to bridge the gap is possible (Ibid).

h) To discourage miss-information

The objective of communication is not only to pass and exchange policies, rules, orders, procedures, and but also to avoid distortions in communication. This function includes discouraging the spread of miss-information, rumors, gossip, and release of emotional tensions by the workers and so on (Ibid).

i) Suggestions and Complaints

Another objective is to encourage ideas and suggestions from subordinates for improvement in the product and working conditions for the reduction in the time or cost involved and for avoidance of waste of raw material 
(Ibid)

\subsection{The Roles of Public Relations Officers}

In general, public relations professionals can be the communication managers who organize and integrate communication activates or they can be communication technicians who primary write and construct messages.

According to Broom and Smith (1979:187), there are four roles of public relations (PR), these are:

$\checkmark$ Expert prescriber: is similar to the role a doctor performs with a patient. These professional's mission to diagnose PR problems and prescribe solution.

$\checkmark$ Production Technician: this role requires executing strategies with the communication tactics of newsletters, position papers, media placements, website content, speeches, blogs and social media message. Practitioners in this role are usually not involved in defining problems and developing solutions, but base their factices on the technical skill of writing.

$\checkmark$ Communications facilitator: practitioners in this role or inter me diaries between the organization and its various publics. Their task is to promote two-way interactions so the lines of communication remain open.

$\checkmark$ Problem solving facilitator: these practitioners are part of the management function team and collaboration with other team members in tackling PR issues. Example, crisis managements. They guide other members of the team in systematically addressing PRs matters:

To help the management in the preparation, interpretation, adoption and evaluation of public relations programmers and policies.

To undertake personal relations research that will keep the management continuously informed so that sound decisions may be made on matters to public relations policies.

- To design an effective performance appraisal system for the use of the management to provide a current inventory of media relating to public relations in organization.

- To undertake a programmer of education, training the staff of the public relations department to develop them.

- To develop an effective internal and external communication system for timely integration.

- To establish the mechanism for the administration of personal services that is delegated to the public relations department.

- To control the PR department and presenting and implementing, all public relations policies and activities

- To convey and interpreting to the management information on public attitudes and views, about the company and/or industry it serves.

- To liaison with the personal department on all matter relating to disseminating of internal information and the company's employee publications. (K.R. Balan).

\section{Methodology}

In order to conduct this study, both qualitative and quantitative research methods were employed. The reason why mixed approaches had been applied was that they enabled the researcher to yield the detail explanations for open-ended questions, and short clear answer for close-ended questions.

Descriptive survey of research design was used. There are two reasons why this design was selected. The first reason is that it enabled the researcher to identify and examine the existing situation in the study at hand. According to Kumar (2006:59) descriptive survey serves as direct sources of valuable knowledge concerning human behaviors. For the other reason, this research design lets the researcher to use flexible approach when vital issues are raised during the study.

For the purpose of the study, researcher employed convenience-sampling technique for the participant selection till to get sufficient date from the respondents. The survey was made when the external public came to get service the from the communication department of Seka. Using convenience sampling, 50 respondents were study sample. Out of which, 31 males and 19 females And two PR practitioners were also purposely selected as the research participants for the interview.

This research included both primary and secondary sources of data. The primary sources had been the PR practitioners of Seka Chekorsa communication office and the internal and external publics of the organization. And secondary data were collected from documents of the department or office in the district.

In order to validate the result of the research, questionnaire, interview, document analysis were used tools of data collection. Questionnaire survey was made to the public. Interview was one important research tools that had been employed in order to get in depth information from the respondents. For this reason, semistructured interview was used for all interviewees, the interview questions were opened with public relation experts of the organization. This instrument was especially designed to see or analyze appropriate documents of 
the department like organizational news release, brochures and yearbooks. Therefore, the tool is paramount crucial to defect the existing profile in the organization.

The collected data was analyzed through both qualitative and quantitative approaches. The responses of close-ended questionnaires had been tabulated and analyzed using statistical tools such as percentages and graphic representation. However, interview, open-ended questionnaires and document analysis were analyzed using qualitative methods of data analysis through description and narration.

\section{Results and Discussion}

This part discusses about the data collected from questionnaire respondents and interview informants. The first part focuses on the discussion of data collected from questionnaire respondents. The next part focuses on the result and discussion of date from interview informants.

\section{Table 4.1: Background of the respondents}

\begin{tabular}{|c|c|c|c|}
\hline \multicolumn{2}{|l|}{ Item } & \multicolumn{2}{|c|}{ respondents } \\
\hline & & \multirow{2}{*}{$\begin{array}{l}\text { frequency } \\
31\end{array}$} & \multirow{2}{*}{$\begin{array}{l}\text { percent } \% \\
62 \% \\
\end{array}$} \\
\hline Sex & Male & & \\
\hline & Female & 19 & $38 \%$ \\
\hline \multicolumn{2}{|c|}{ Total } & 50 & $100 \%$ \\
\hline \multirow[t]{3}{*}{ Age } & under 25 & 10 & $20 \%$ \\
\hline & $26-35$ & 18 & $36 \%$ \\
\hline & $36-47$ & 15 & $30 \%$ \\
\hline \multicolumn{2}{|c|}{ Total } & 50 & $100 \%$ \\
\hline \multirow[t]{5}{*}{ Educational Status } & Degree & 6 & $12 \%$ \\
\hline & diploma & 21 & $42 \%$ \\
\hline & certificate & 7 & $14 \%$ \\
\hline & grade $9-12$ & 15 & $22 \%$ \\
\hline & grade $1-8$ & 5 & $10 \%$ \\
\hline \multicolumn{2}{|c|}{ Total } & 50 & 100 \\
\hline
\end{tabular}

Source: compiled from own survey data

According to the data gathered, $62 \%$ of respondents are males and $38 \%$ females. As regards age, $36 \%$ of the informants are in between the age group of $26-35$. And $30 \%$ of them are in the age group between $36-47$. The remaining $20 \%$ and $14 \%$ of them are under 25 and above 47 respectively. Regarding education, status, the data reveals that $42 \%$ and $12 \%$ of the informants are diploma and degree holders respectively. Moreover, $22 \%$ of them are high school students (grade 9-12). The rest $14 \%$ of study sample have earned certificates while $10 \%$ of them are still between grades 1-8. The data shows that the respondents between the age group 26-36 have better educational status. Thus, it is possible to deduce that this (their educational status) helps them to be reliable to provide genuine information/data.

Table 4:2: The role of PR persons in building good image of the organization

\begin{tabular}{llll}
\hline № & Ratings & No of respondents & Percentage \\
\hline 1 & very high & 9 & $18 \%$ \\
2 & High & 25 & $50 \%$ \\
3 & Medium & 14 & $28 \%$ \\
4 & Low & 2 & $4 \%$ \\
5 & very low & 0 & $0 \%$ \\
\hline & Total & 50 & $100 \%$ \\
\hline
\end{tabular}

Source: compiled from own survey data

The data in the table above shows that $18 \%, 50 \%, 28 \%, 4 \%$, and $0 \%$, of the informants said 'very high', 'high', 'medium',' low', and 'very low' respectively. As regards the other alternatives, the respondents confirm that the role of PR persons in building good image of the organization is 'high'. This shows PR persons have a great role to play in building a good image the organization. 
Table 4.3: The contribution of communication in PR practices with regard to building or maintaining relationship between the internal or external and the organization

\begin{tabular}{llll}
\hline No & Ratings & No of respondents & Percentage \\
\hline 1 & very high & 5 & $10 \%$ \\
2 & High & 28 & $56 \%$ \\
3 & Medium & 13 & $26 \%$ \\
4 & Low & 2 & $4 \%$ \\
5 & very low & 2 & $4 \%$ \\
\hline & Total & 50 & $100 \%$ \\
\hline
\end{tabular}

Source: compiled from own survey data

The above table depicts that $10 \%$ of the respondents responded 'very high'; $56 \%$ high, $26 \%$ medium. And similarly $4 \%$ and $4 \%$ of them replied 'low' and 'very low' respectively. Most of the informants (28/56\%) said 'high. This shows that the contribution of communication in PR practices is great in creating and maintaining relationship between the internal and external publics and the organization. Therefore, communication in PR practices plays a pivotal role in creating and maintaining a good relationship between the organization and the publics as well.

Table 4.4: The role of PR practitioner regarding to the advantages of both organization and its publics

\begin{tabular}{llll}
\hline № & Ratings & No of respondents & Percentage \\
\hline 1 & very high & 7 & $14 \%$ \\
2 & High & 22 & $44 \%$ \\
3 & Medium & 11 & $22 \%$ \\
4 & Low & 10 & $20 \%$ \\
5 & very low & 0 & $0 \%$ \\
\hline & Total & 50 & $100 \%$ \\
\hline
\end{tabular}

Source: compiled from own survey data

The data in the table above shows that $14,44 \%, 22 \%$, and $20 \%$, of the respondents reflected 'very high', 'high', 'medium' and 'low' respectively, but the option 'very low' was not chosen. From this we can infer that the role of the PR practitioner, with regard to the advantages of both organization and the publics is tremendous. This might mean that a PR practitioner works for the benefits of both organization and the publics. And from this discussion, we can deduce that the PR practitioner works to create a win-win situation since the advantages are for both the organization and the publics (that is internal and external publics).

Table 4.5 Qualities of PR persons in creating the mutual understanding and benefits for the internal or external publics in the organization.

\begin{tabular}{llll}
\hline No & Ratings & No of respondents & Percentage \\
\hline 1 & very high & 15 & $30 \%$ \\
2 & High & 21 & $42 \%$ \\
3 & Medium & 11 & $22 \%$ \\
4 & Low & 2 & $4 \%$ \\
5 & very low & 1 & $2 \%$ \\
\hline & Total & 50 & $100 \%$ \\
\hline
\end{tabular}

Source: compiled from own survey data

According to the data in the table, $30 \%$ of the respondents answered 'very high', $42 \%, 22 \%, 4 \%$ and $2 \%$, of them replied 'high', 'low', and 'very low' respectively. This shows that the greatest number of the respondents responded 'high'. And this demonstrates that PR person has a numerous qualities of creating the mutual understanding and benefits for internal or external publics in the organization. From this, we can say that PR practitioners work towards creating mutual benefits for both an organization and the publics' interest. 


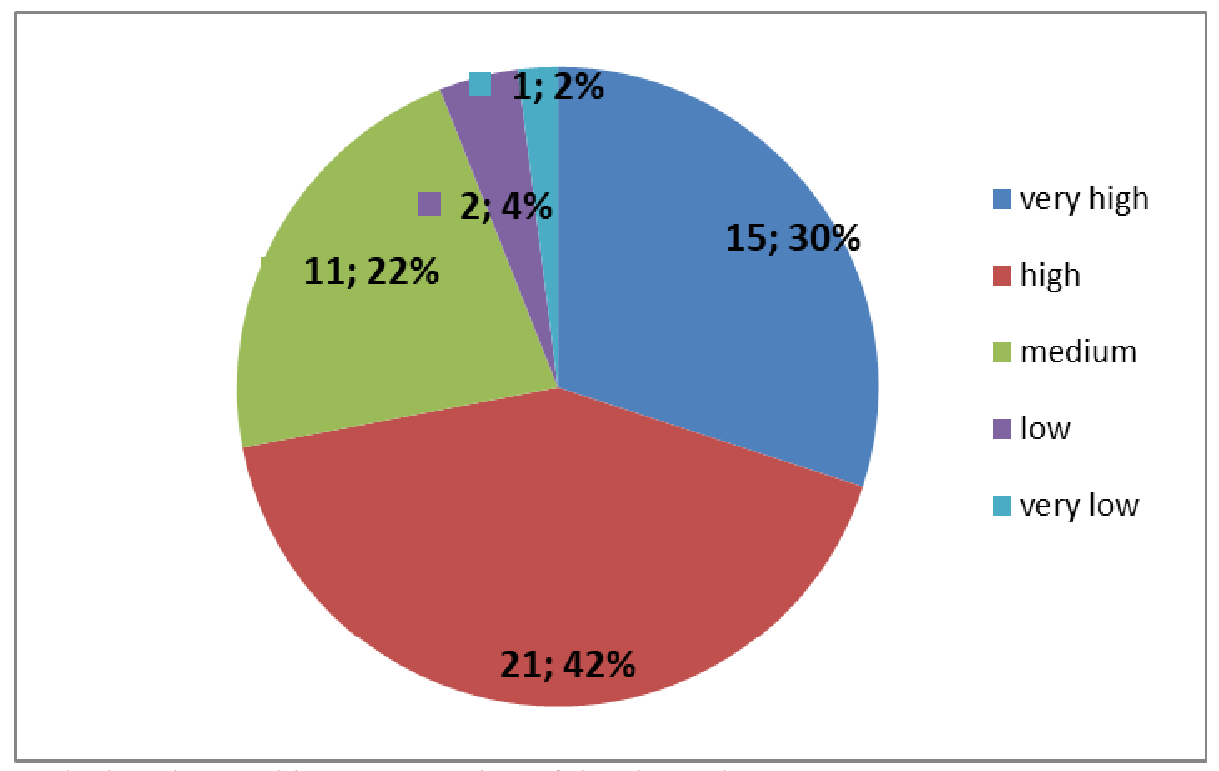

This figure depicts the graphic representation of the above data.

Table 4.6: The status of PR practices in identifying public problems and finding solutions.

\begin{tabular}{llll}
\hline № & Ratings & No of respondents & Percentage \\
\hline 1 & very high & 6 & $12 \%$ \\
2 & High & 24 & $48 \%$ \\
3 & Medium & 16 & $28 \%$ \\
4 & Low & 6 & $12 \%$ \\
5 & very low & 0 & $0 \%$ \\
\hline & Total & 50 & $100 \%$ \\
\hline
\end{tabular}

Source: compiled from survey data

The data presented in the table above demonstrates that the majority of the respondents responded 'high' and none of them replied 'very low'. This indicates that the public relations practices in finding out public problems and looking for solution is high. Additionally, we can understand that PR practitioners work to resolve problems and give practical solutions that satisfy both the organization and the publics. In short, the status of PR practices is great in identifying problems and finding solutions for both the organization and its publics (i.e. both internal and external publics).

Table 4.7: Do public relations persons motivate the publics?

\begin{tabular}{llll}
\hline № & Alternatives & No of respondents & Percentage \\
\hline 1 & Yes & 43 & $66 \%$ \\
2 & No & 7 & $14 \%$ \\
\hline & Total & 50 & $100 \%$ \\
\hline
\end{tabular}

Source: compiled from own survey data

According to the table, $86 \%$ and $14 \%$ of the respondents answered "yes" and "no" respectively. This portrays that PR practitioner highly works towards the publics.

The PR practitioner motivates the publics through effective communication employing various approaches such as holding discussions and empowering the publics in any way possible.

In terms of interview, the researcher made five interview questions with two PR practitioners in Communication office of Seka Chekorsa district. The result and discussion of the interview questions are analyzed and interpreted as follows:

I. The duties and responsibilities of PR professional

The main duty/role of the PR practitioners is to create awareness in organization leaders along with its publics.

Communication facilitator: - practitioners are intermediaries between the organization and its various publics. Their task is to promote two way street interactions. So, the lines of the communication remain open. From this, we can understand that PR practitioners have immense roles and responsibilities for keeping two way street communication of organization and its publics.

Problem solvers: practitioners are part of the management function team and collaborators with other team members in tackling problems.

$\checkmark$ Serving the public interest along with organization

$\checkmark$ Counseling the top management

$\checkmark$ Implementing the policy and strategy of the organization. This entirely shows that PR 
practitioners have multi-dimensional roles.

As regards the definition of PR and its purpose, Wilcox et.al (2003:6) stated: "public relations is the art and social science of analyzing trends, predicting their consequences, counseling organization leaders and implementing planned program of action which serve both the organization and the publics."

II. The contribution of communication in PR, pertaining to establishing and maintaining relationship with the organization publics

Communication (particularly interpersonal communication) is the life blood in PR. Effective communication has a great contribution in creating and maintaining relationship between the organization and its publics. Through effective communication, PR practitioner puts an action into decisions that have been made a head of time. PR communication is about accomplishing the plan that has been prepared. This reveals that PR communication has a great contribution in searching solution for public problems.

Moreover, communication in PR has a tremendous contribution in influencing customers regarding the usage of fertilizers in the Seka Chekorsa. By using fertilizers, most farmers in the Seka are benefited. This is the result of effective communication through telling people how the use the fertilizers effectively. This shows that communication plays a dominant role in changing the attitude or perception of the publics. Public relations and communication are the sides of the same coin. This means communication is the backbone of PR. Without communication, there is no PR or organization. In a nutshell, according to information reflected from practitioners, the contribution of communication in PR, establishing and maintaining relationship among the organization and the internal or external publics is enormous.

III. The Challenges that PR practitioner encounter in the department

Public relations practitioner has varieties of activities to work in different sector of the firm in order to be effective in achieving goals and mission implementation.

We cannot totally say PR department is effective in its activities in Seka Chekorsa district. There are problems that hinder them from working effectively. The department's main problems are limitation or shortage of work force, shortage of necessary materials and in adequate budget. Let us see the problems in detail.

\section{A. Work Force}

The department has shortage of man power that performs different activities. The limited number of the practitioners has made the department not to have different sectors that make practices easy and comfortable. This indicates that the department is not well developed in terms of trained practitioner.

\section{B. Necessary Materials}

The department has shortage of necessary materials. It does not have materials like micro phone, video camera and photo camera. The practitioners work by establishing relationship with other organizations or media in order to find those useful materials. From this, we can conclude that the department is not well equipped in terms of materials. Thus, this brings PR practices weaker in Seka Chekorsa District.

\section{Budget}

The department does not have enough budgets that help the practitioner to carry out the activities effectively. This is the major challenge that hampers the PR practice in the district.

\subsubsection{The main objectives of PR department in Seka District}

Since PR department was established, it has its own objectives to achieve or satisfy both the organization and public's interviews.

$\checkmark$ The department regards the organization and publics as two sides of the same coin. This means, they work for mutual interest and mutual understanding.

$\checkmark \quad$ They work on creating better communication between the organization and its publics.

$\checkmark$ They also carry out activities such as informing education the publics about social and economic progress of the district.

$\checkmark$ Preparing different media of communication like public meeting documentary film, brochures and others in order that they influence the publics.

$\checkmark$ They announce the overall developmental activities of the society by using different regional media.

$\checkmark$ The major objective of PR department is to promote good relations, understanding with employees within the organization.

$\checkmark \quad$ PR practitioners perform listening to the societal problems and searching for solutions through discussion with the top management and with the responsible persons.

Based on information provided above, the objectives of PR department in the woreda are numerous. Thus, according to the interviewees, the objective of PR practitioners is multi-dimensional and they work for the seka of the organization as well as for publics.

\section{Communication tools of PR department in Seka Chekorsa District}

To make PR practices effect; PR department used different communication tools. These tools are helpful for disseminating information to publics in different places in the woreda. The predominant communication tools 
that PR department uses are newspapers and magazines, exhibitions and documentary films and brochures. These tools are used when there are events like conference, public ceremonies and public celebrations and developmental issues. Most of the communication tools like newspapers and magazines exhibitions and documentary films are used when they make coordination or collaboration with other media. But the internal and external communication tools such as, brochures, yearly book, hand books and others

\section{Summary and Conclusion}

In the study, the researcher tried to find how public relations practices are carried out in Seka Chekorsa District Administration. Most importantly, the duties or roles and responsibilities of PR practitioner, the contribution of communication in PR, the objectives of PR department, the challenges of PR practitioners face and the communication tools in the district all have been analyzed and interpreted.

The organization, the PR department in Seka has tremendous roles to play regarding to overcoming the societal problems, creating and maintaining good relationship with its publics, facilitating communication and equipping the society with the information and the on going development.

Furthermore, the PR department in the woreda has also objectives with regard to executing programme as well. For example, counseling the top management, implementing the policy and strategies of the organization and working for mutual benefits are the main objectives of PR department in Seka Chekorsa.

On the other hand, the work of the department is not so effective and successful. There are some problems which hinder the practices of PR from being materialized the department. For instance, the problems are lack of professional man power, shortage of materials and lack of enough budget have made the department/organization unsuccessful.

The other thing is that the department does not have its own communication sector to have direct relation with its publics. Instead, it is depending on different media sectors to forward information to the publics. However, the department has its own internal communication tools like brochure, handbook, yearly book and others.

\section{Recommendations}

Based on the findings stated in the conclusions section, the following recommendations are forwarded for the department or organization. The practices of PR in Seka are good, but it will be by far better effective if:

a. The organization employs PR practitioners who are skilled in the field of language, journalism and communication.

b. The department has its own communication sector instead of working depending on other's media

c. The PR practitioners are offered different trainings on capacity building with regard to communication competence and other significant knowledge.

d. The department has adequate budget

e. The organization gives due attention to bring journalistic materials or equipment for message transmission.

\section{References}

Barany. J (2002). Introduction to mass communication and culture $2^{\text {nd }}$ ed: USA, Rumford press

Bernays. E (1945). Public Relation and Propaganda. USA: 37Rumford Press

Broom. C and Smith. G.D (1979). Role and Responsibilities of public Relations. New Delhi: A. I Publishing Company

Building. B (2007). Marketing Definition's Public Relation. Retrieved on February, 1, 2015 from http://www.building brand, com/definition of public relation

Cutlip, scott (1995). Public Relation History: from $17^{\text {th }}$ to $20^{\text {th }}$ centrury: Lawrence: Earlbaum Associates

Daramo.A.C (1996). Effective Public Relation. Englewood Clifts, NJ: Prentice-Hall

Free Management Library (2007). Basic Definitions: Advertising, Marketing, promotion, public relations and publicity and Sales. Retrieved on February 3, 2015 from http://www.managementhelp.org.

Grunning. J.E and Hunt. T (1976). Managing Public Relations: New York: Holt, Rinohart and Winston

Jefkins. F (2004). Public Relation Contemporary Issues and Techniques. UK: Heinemann

Kumar Y.S (2006).Fundamental of Research Methodology and Statistics. New Delhi: New Age International (p), td.

Porta. M (2006). A Dictionary of Epidemiology Oxford: Oxford University Press

Public Relations Society of America (1982). Public Relation Defined. Retrieved on February 6,2015 From $\mathrm{http}: / / \mathrm{www}$.prsa.orga/about/public relation defined

Selfadin Aferano(2014).Assessing the Communication Strategies of PR Office of Adama City Administration: Unpublished BA thesis 
Seitel. F.P (2004). The Practice of Public Relations, prentice. Hall- Inc: a Person Education Company

Zelalem Dereje(2014).Assessment on the Factors that Affect Mekele CITY Culture AND Tourism due to lack of Public Relations Service:unpublished BA thesis 